\title{
Some Points in the Morphology and Physiology of Fasciated Seedlings.
}

\author{
BY \\ T. REED, A.R.C.SC. \\ Senior Demonstrator of Biology, Guy's Hospital Medical School (University of London).
}

\section{With nine Figures in the Text.}

A FASCIATION is a form of abnormality in which the organ conin two ways, (I) by the fusion of organs which are ordinarily distinct, or (2) by the lateral expansion of an organ at its growing point.

The study of abnormalities in general has always occupied a more or less prominent place in botanical science, but the point of view from which they have been regarded has largely been that of the 'curious'. The two following quotations show in a striking manner the attitude of the botanists in the middle of the nineteenth century and the beginning of the twentieth. M. T. Masters (13), in his 'Vegetable Teratology', is describing the attitude of the botanists of the day, and says of malformations, "They have been too long looked upon as monsters to be shunned, lazuless deviations from the ordinary rule and unworthy of the attention of botanists.' Hugo de Vries (21) in 1905 says, 'Monstrosities are often considered as accidents, and rightly so from the morphological point of view, but physiology excludes all accidentality. Some internal hereditary quality is present though often latent, and the observed abnormalities are to be regarded as responses of this innate tendency to external conditions. Monstrosities should always be studied by physiologists from this point of view.'

Looked at from this point of view abnormalities become invested with a much greater importance.

The normal development of an individual is the result of two factors, the inherent tendencies of the organism and the external influences to which it is subjected. An abnormal form is one which deviates to any considerable extent from the normal or 'usual' form, as a result of the disturbance of one or other of these factors. If, however, the organism

[Annals of Botany, Vol, XXVI. No. CII. April, 1912.] 
deviates from the 'usual' course of development because of its being subjected to new external influences, then the term abnormal should cease to have any meaning so far as that individual alone is concerned, for obviously if it has been caused to deviate from the usual path of development because of certain specific new conditions, then that altered form is merely a new form which fits in with new conditions; that is to say, it is normal in so far as it is an individual which has developed as a result of inherent tendencies and external conditions, but abnormal when considered in relation to the 'type form'.

Within recent years many experimental facts have been obtained which go to show the truth of de Vries's suggestion.

It has been shown by G. Klebs (10), amongst others, that an alteration in the nutrient medium of an organism may have an important effect upon the form or phase of life of the individual concerned, and A. F. Blakeslee (1) has shown that it is possible to cultivate distinct physiological races by varying the conditions of culture. Similarly with the variations in Oenothera Lamarckiana, which de Vries discovered near Amsterdam in 1886 . In its native soil the form had proved fairly constant, but in the potato field at Hilversum, where it met with new conditions, it soon began to assert its power to vary by producing ' abnormal' forms in the shape of fasciations and pitcher leaves, annual and triennial forms in place of biennials, and numerous other forms.

While altered conditions of culture may only result in a temporary 'variation' of the organism, it is important to notice that the individual can apparently be made to change in some degree.

It does not seem to be a far cry from these altered forms to those recently obtained by D. T. MacDougal (12). This observer injected solutions of sugar, zinc sulphate, \&c., into the ovaries of flowers of Oenothera biennis and Raimannia odorata, and from the ovules of these plants he obtained seeds which on germination gave rise to individuals which deviated to a considerable extent from the normal parental type. These observations are particularly interesting in that not only were the individuals very different from the parental type, but also in that the derived forms have bred true over a period of five years. In other words, it would appear that we have here an 'abnormality' induced by a specific alteration of conditions of growth, i.e. an induced mutation. The 'derivative' form also breeds true to type when placed in the habitat of its parental type.

In nature it is not always easy or possible to analyse all the factors which may be operating on the individual, but it seems probable that there must be factors the effects of which, either singly or collectively, may be to induce modifications in the organism. What the actual mechanism is would be difficult to determine. Is it a definite chemical action of the disturbing substance on the constitution of the plant body, or is it an alteration in the 
physical environment which 'permits' the variability of the organism to assert itself anew?

Abnormalities in the form of fasciations are of fairly frequent occurrence, and many examples have been described. C. Linnaeus (11) speaks of fasciations in his 'Philosophia Botanica'. He discusses their nature, and concludes that fasciated stems are due to the formation of an unusual number of growing points which become coherent, so that a whole bundle of shoots emerge as one. He says, 'cum plures caules connascuntur, ut unus ex plurimis instar fasciae evadet et compressus.'

At the beginning of the nineteenth century A. P. de Candolle (2) began to study malformations, but principally from the morphological point of view.

T. A. Knight $(8,1822)$, in a letter to the Secretary of the Horticultural Society, gives us some interesting facts concerning the production of fasciation in the Cockscomb (Celosia), perhaps one of the most widely known fasciations. He found that by applying larger quantities of manure he could produce larger and flatter specimens of the flower stalk of Celosia. By manuring the soil with ' one part of unfermented horse-dung fresh from the stable and without litter, one part of burnt turf, one part of decayed leaves, and two parts of turf, the latter in lumps about half an inch in diameter', and by applying 'liquid manure of steeped pigeon-dung in water', he could produce fasciated flower stalks eighteen inches wide. This fasciation is interesting in that the fasciated stem has now become normal and its inheritance is absolute. It is further instructive in that it is a definite example of a fasciation that has been induced by altered external conditions, the external condition which promotes fasciation being the superabundant nourishment.

A. Moquin-Tandon (15) in I 84 I published his 'Eléments de tératologie végétale', wherein he discusses the significance to be attached to malformations. In this work he makes the interesting observation that the seeds of a fasciated Circium reproduced the same condition in the seedlings.

W. Hinks (7) in 1853 described instances of fasciation in Primula vulgaris, Hieracium aureum, Ranunculus bulbosus, Bunium flexuosum, Cotoneaster microphylla, \&c. He states 'that these malformations are due to the operation of causes or principles, the ordinary operation of which produces the normal structure of the species'. He evidently recognized that ' extraordinary structures' were the result of ' extraordinary influences'. He, however, goes on to say that 'fasciated stems seem to be best explained on the principle of adherence of a number of buds which have arisen in close proximity owing to the presence of superabundant nourishment, especially if accompanied by check or injury'. He also combats the argument that fasciated stems are due to the dilation of a single stem, as had been supposed by many people. 
M. T. Masters (13) published his 'Vegetable Teratology' in 1869 , and there gives a host of examples of plants showing various forms of malformation. He recognizes that malformations are to be regarded as irregularities differing from variations mainly in their wider deviation from the customary structure and in their more obvious dependence on external conditions, and by their smaller liability to be transmitted by inheritance. He further goes on to say 'that it is even possible that malformations, especially when they acquire a permanent nature and become capable of reproducing themselves by seed, may be the starting-point of new species, as they assuredly are of new races, and between races and species he would be a bold man who would undertake to draw a hard and fast line'. Thus even as early as I869 Masters thought it not improbable that mutations, caused by external influences, might give rise to new species.

Coming to more recent times, A. Braun, Celakowsky, Worsdell (23), Goebel $(4,5)$, Vöchting (18), and de Vries $(19,20,21,22)$ have given us many interesting observations on malformations.

$\mathrm{K}$. Goebel $(4,5)$ states that it was mainly owing to the study of malformations that the idea of the foliar nature of the stamen came to be recognized. 'It is rather to the causes which condition the deviation from the normal development that we ought to pay most attention.' If by altering the external conditions an alteration can be induced in the organism, then we are in a fair way towards throwing some light on the great question of organic form. He gives examples of fasciations in Taraxacum officinale and mentions that it is only well-nourished specimens which show this phenomenon.

H. de Vries $(19,20,21,22)$ describes several examples of fasciated stems in Taraxacum officinale, Thrincia hirta, Picris hieracioides, and Crepis biennis. The latter gives off about 30 per cent. to 40 per cent. of heritable forms. He states that weak seedlings are not favourable examples for obtaining malformations, but strongly nourished plants should be taken. In speaking of stems which show biastrepsis and fasciation, de Vries (19) also states that 'most monstrous plants require much manure ; manure can hardly be given in excess; the richer the soil the better the proportion of twisted stems'.

A. D. Knox (9) describes instances of fasciation in Oenothera biennis and $O$. cruciata. She describes the anatomy of the fasciated stems and gives an account of the degree of heritability of the malformation. The causes of fasciation in these cases are said to be two, (I) injury to the growing point by insects, and (2) superabundant nourishment. She concludes that 'given similar conditions of culture the factors involved in the production of fasciations are the specific mode of attack of insects, the character of the plant, and the rapidity of development. The second of the three 
appears to be of most importance.' A point worthy of special notice is that the fasciations usually just precede the date of flowering, i. e. at a time when the carbohydrates of the plant will be very abundant.

Molliard (14) describes cases of fasciation in which he found the apices of the plant injured by insects. attacks.

J. Peyritsch (17) found fasciations which he thought were due to fungal

T. Petch (16) states that fasciations are frequently. found in Hevea Brasiliensis. The trees affected are principally young trees. He thought that in some instances fasciation was due to attack of insects and Fungi, but in the majority of cases no definite cause could be stated.

R. H. Compton (3) describes the anatomy of a 'ring fasciation' in the Mummy Pea, Pisum umbellatum (Miller). This form also breeds true, its peculiar character behaving as a simple recessive in crosses with the normal type.

A review of the historical evidence leads us to conclude that fasciations are due to at least two causes. Firstly, the presence of superabundant nourishment and suitable conditions for rapid development ; and, secondly, the sudden arrest of the activity of growing points due to insect and fungal attacks. It would appear, though, that a third factor ought to be added to account for the many cases of fasciation which appear for no apparent reason, but which might very easily be caused by mechanical injury to the growing point.

In any case, it now appears to be fairly certain that whatever the inducing factor may be there must be present within the plant a considerable quantity of elaborated sap to supply the demands of increased meristematic activity, and it may well be that this is the essentially determining cause in all.

In the present investigations seedling plants of Leguminoseae were chiefly used, but others were introduced for purposes of comparison.

The seeds were germinated in various soils, and when the plumular shoots had developed a length of about an inch or so the apical bud was cut away and the seedling allowed to continue its growth:

Two types of seedling were used, the epigeal and the hypogeal types.

\section{A. HỵPOGEAL.}

\section{Phaseolus multiflorus.}

The plants were grown in both soil and sawdust. In about two days the radicle had penetrated the testa and grown down into the substratum. Two or three days later the epicotyl and plumular leaves had appeared above the soil and attained a length of about an inch. The main portion of the epicotyl was removed and the seedlings allowed to continue 
their growth. As a consequence of the arrested growth at the stem, apex shoots were developed in the cotyledonary axils (Fig. I, $b$ ). The

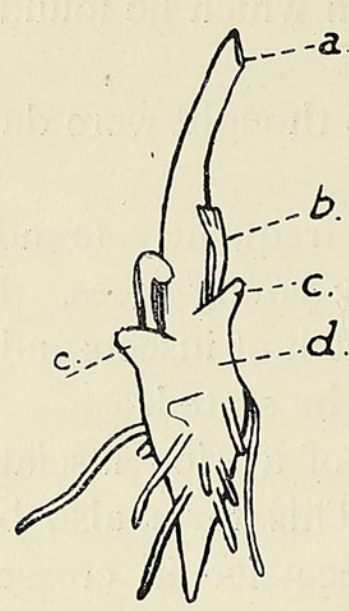

FIG. I.

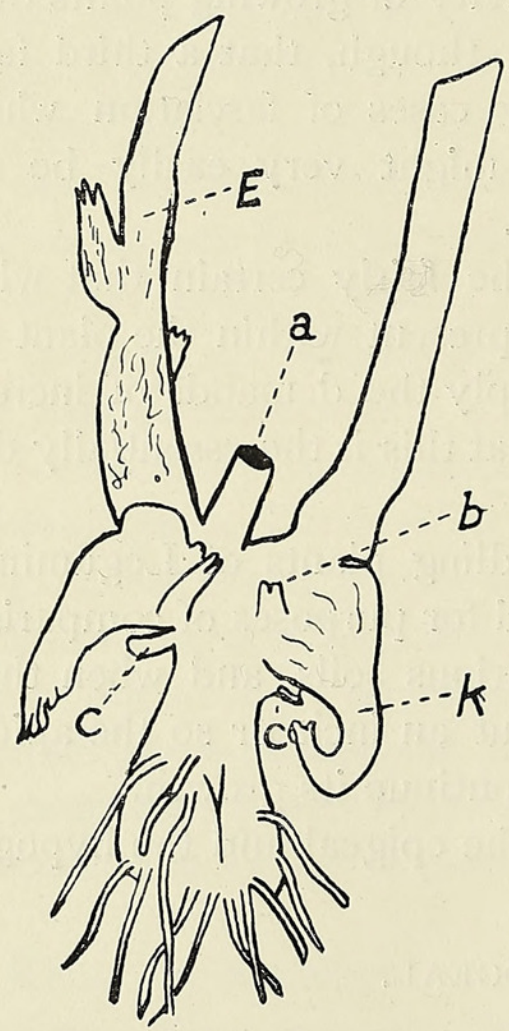

FIG. 3.

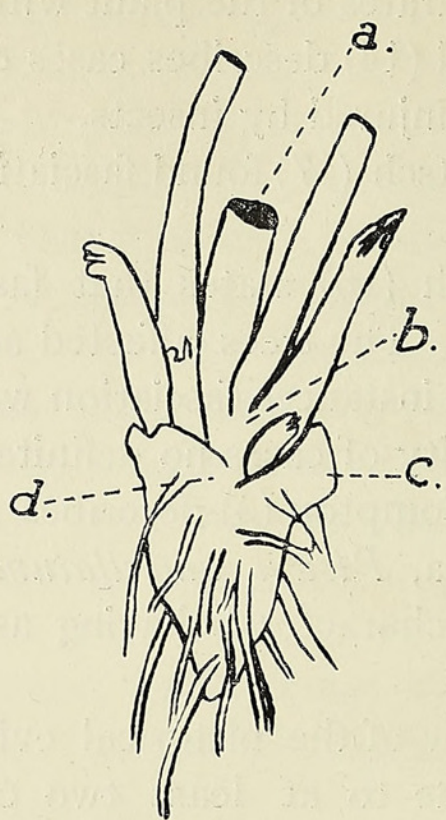

FIG. 2.

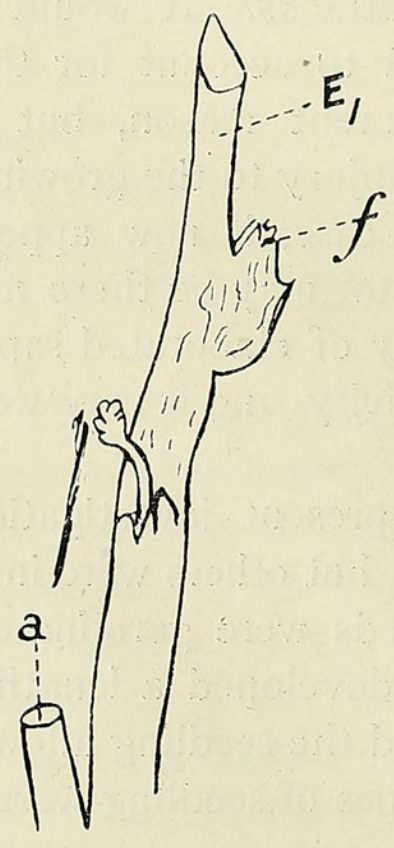

FIG. 4.

FIGS. I-4. $a$, cut end of plumular shoot. $b$, axillary shoots. $c$, cotyledonary petiole. d, hypocotyl. $E$, fasciated shoot. $E_{1}$, the reverse side of $E$. $k$, twisted and fasciated shoot.

buds from which these shoots are developed normally remain dormant. Many of these shoots, instead of following their normal course of development, were found to show very pronounced fasciations and biastrepsis 
(i. e. twisting). If the further development of these shoots is also inhibited by the removal of their apical buds, more fasciated and twisted shoots are produced at their bases until quite a tangle of such shoots is formed in the cotyledonary axil. Such seedlings are shown in Figs. 2 and $3, b$. If the seedling is now permitted to continue its growth it does so for a short time only, and sooner or later all further growth ceases and the plant dies.

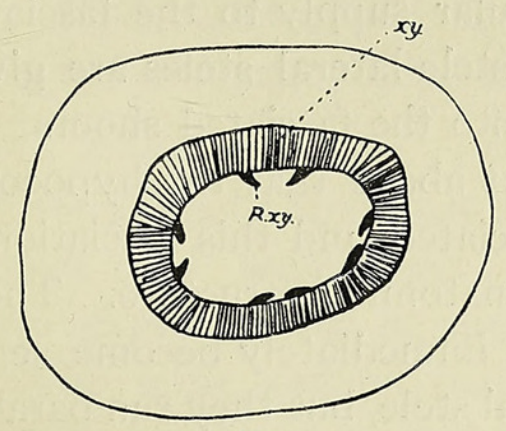

FIG. 5.

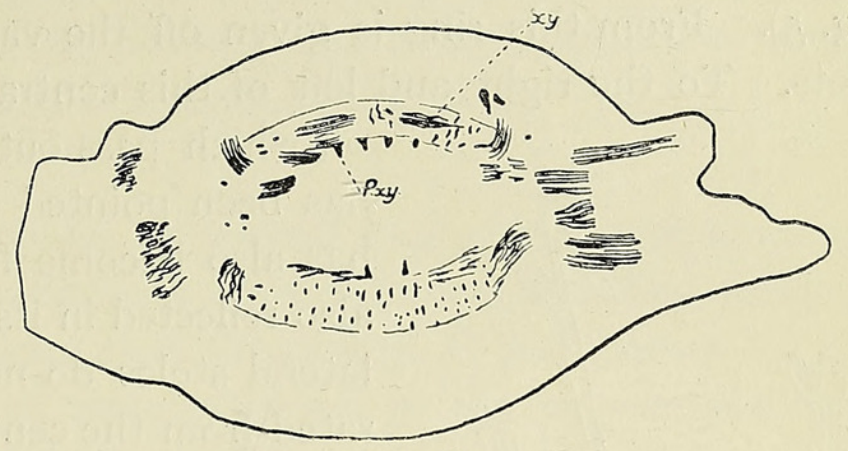

FIG. 6.

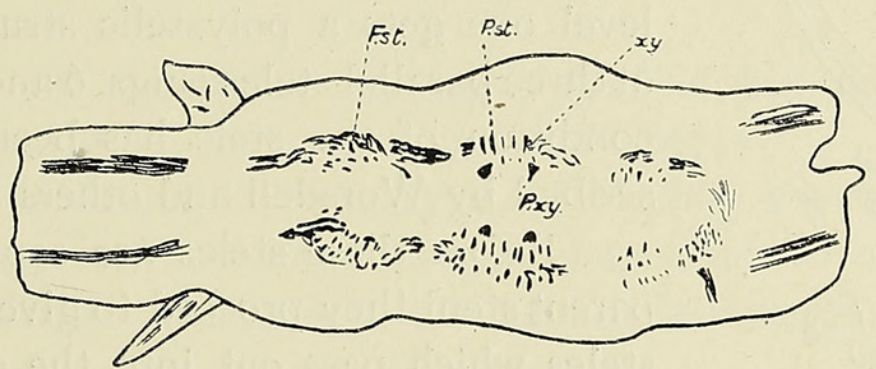

FIG. 7.

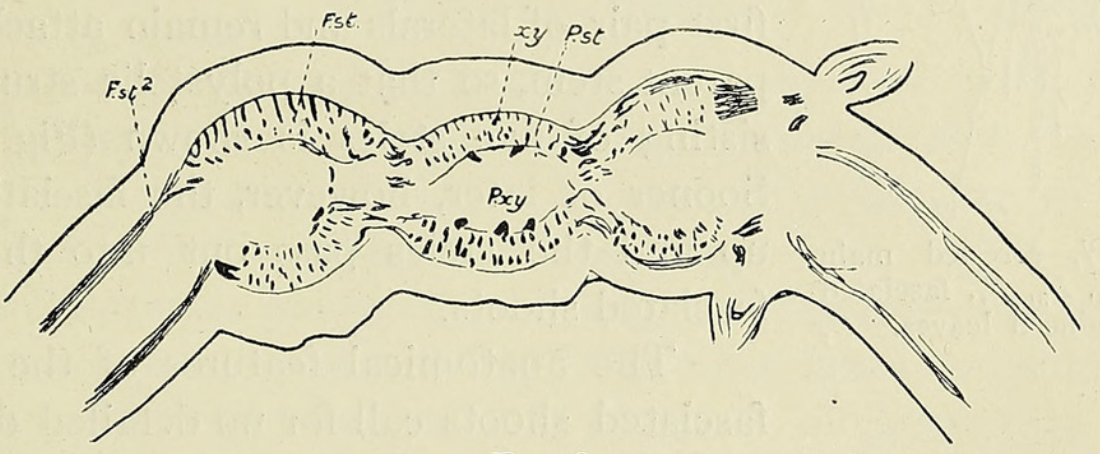

FIG. 8.

Figs. 5-8. $x y$, secondary xylem. P.xy., protoxylem. P.st., plumular stele. F. Ft., F.st. ${ }^{2}$, first and second fasciated shoot steles.

In addition to the development of the axillary fasciated shoots, the hypocotyl also develops enormously and presents a fasciated appearance (Fig. 2, d).

The leaves which are laid down on the fasciated shoots also remain small and in many cases do not even unfold from the bud (Fig. $4, f$ ).

The development of the root system appears to be quite normal.

The power of the plant to respond to various stimuli also appears to be 
interfered with. The shoots twist and curl in all directions, with an apparent disregard for all heliotropic and geotropic stimuli (Fig. $3, k$ ).

Anatomy of fasciated shoots. As is well known, four bundles pass into the hypocotyl from each cotyledon. In passing down the hypocotyl these become orientated, so that a tetrarch stele is formed in the root.

Secundary thickening commences very early, so that in a young seedling an almost complete vascular ring is found near the top of the hypocotyl (Fig. 5). From this ring is given off the vascular supply to the fasciated shoots. To the right and left of this central stele lateral steles are given

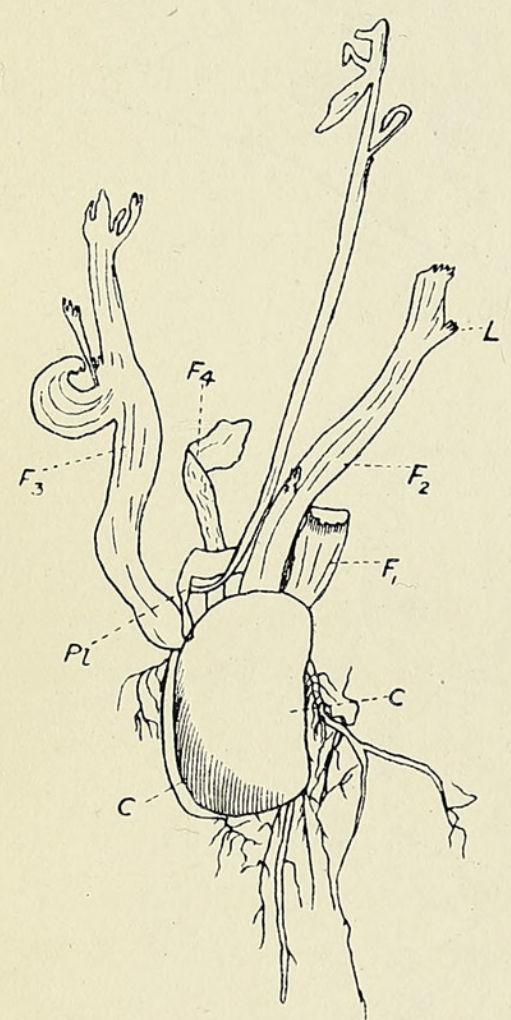

FIG. 9. $P l$, arrested main shoot. $F_{1}, F_{2}, F_{3}, F_{4}$, fasciated shoots. $L$, reduced leaves. $C$, cotyledons. off which pass out into the fasciated shoots. It has been pointed out above that the hypocotyl has also become fasciated, and this fasciation is also reflected in its anatomical structure. These lateral steles do not immediately become separated from the central stele, but they run parallel with it for some little distance, so that at this level one gets a polystelic structure consisting of three parallel steles (Figs. 6 and 7, F.st.). This condition of the stele has been frequently described by Worsdell and others for other plants.

Before these steles are separated from the parent stem they proceed to give off other lateral steles which pass out into the second fasciated shoots. These steles behave similarly to the first pair of laterals and remain attached to the parent stem, so that a polystelic structure consisting of five steles is shown (Fig. 8, F.st. ${ }^{2}$ ). Sooner or later, however, the fasciation breaks up and the steles pass out into the separate fasciated shoots.

The anatomical features of the individual fasciated shoots call for no detailed description. The normally cylindrical stele becomes laterally attenuated and follows more or less completely the configuration of the malformed shoot. No pronounced abnormal structures were seen in the stele of these shoots, although it is not uncommon to find that the whole arrangement of the stele may be considerably interfered with. On the whole one finds perhaps fewer lignified elements in such vascular tissue, but this may be correlated with the comparatively rapid growth of the shoot and its generally etiolated appearance, and the fact that its subsequent development is also arrested, so that the elements remain in a more or less immature condition.

A case which calls for special mention is one in which the fasciation 
appeared 'spontaneously'; that is to say, the fasciation was not artificially induced by amputation of the growing point. Although I was not able to determine with absolute certainty the immediate factor which brought about the fasciation, a careful examination of the seedling showed that the development of the main shoot had been interfered with and its growth checked. This check may have been due to mechanical injury of the growing point, or the apical bud may have been attacked by a fungus or insects, \&c. As a result of the check the axillary shoots developed and became strongly fasciated. This seedling is figured in Fig. 9.

VICIA FABA.

Seedlings of this plant were also grown and treated in a similar manner to those of $P$. multiflorus. Fasciations were obtained, but they were not nearly so pronounced or numerous as in the case of $P$. multiflorus.

The same general features were observed in the hypocotyledonary anatomy, but never more than three vascular rings were met with.

Pisum SATIVUm.

Seedlings of this plant were similarly treated, but here again, while fasciations were produced, they were few in number.

It will be noticed that the three types of seedling above studied are all of the hypogeal type and all show fasciations to a greater or lesser degree. It was therefore thought desirable to test the power for producing fasciation in epigeal seedlings.

\section{B. Epigeal Types.}

Phaseolus vulgaris (French Bean), $P$. vulgaris (var.?) (Butter Bean), Lupinus Douglassii, Ricinus communis, and Cucurbita Pepo were chosen because of the fleshy nature of their cotyledons or because of the large amount of reserve food available to the seedlings.

The seedlings were grown in pots along with the types already studied, and also grown separately in pots with the other types as controls grown near to them. They were subjected to treatment similar to that which the previously studied types had undergone. Although the cotyledonary shoots developed in many instances, in no case was a fasciation produced.

Is this power of the hypogeal type of seedling to produce fasciations an accidental quality which is not possessed by the epigeal type, or is it that the food reserves of the two types of seedling differ in quality or quantity?

It has frequently been stated by other observers that an abundant supply of food material is necessary for the production of fasciations.

Analyses were made of the seeds of $P$. multiflorus, $P$. vulgaris, and Vicia Faba. For these analyses I am greatly indebted to Mr. T. J. Ward, of the Chemical Department of St. Mary's Hospital Medical School, Paddington. 
In each case the testa was removed from the seed before the analysis was made.

The results of the analyses were as follow:-

\section{Constituents.}

Moisture .

Benzine extract. (Oils, fats, resins, \&c.) .

Alcohol extract. (Tannin, glucosides, and some sugars)

Soluble carbohydrates, as dextrose . $\quad$.

Starch

Cellulose .

Proteids.

Diastatic value as wt. of starch converted by Ioo grm. of bean .

Calcium (as oxalate)

P. multiflorus.
$\begin{array}{r}14.44 \\ 2.72\end{array}$
$\left(\begin{array}{l}\mathrm{I} 1.04) \\ \text { I0.I } 55 \\ 46.35 \\ 2.3 \mathrm{I} \\ 2 \mathrm{I} .64 \\ (3.5) \\ 0 . \mathrm{I} 96 \\ \hline 97.8 \mathrm{II} \\ \hline\end{array}\right.$

P. multiflorus.

\begin{tabular}{c} 
Vicia Faba. \\
$\begin{array}{c}\text { I } 3.305 \\
2.11\end{array}$ \\
$(4.5 \mathrm{I})$ \\
16.004 \\
$37 \cdot 296$ \\
2.09 \\
27.83 \\
$(1.85)$ \\
0.123 \\
\hline $98.75^{8}$
\end{tabular}

P. vulgaris.

I 3.46

$\mathrm{I} \cdot 9^{8}$

(29.99)

$9.8 \mathrm{I}$

43.01

$2 \cdot 15$

$21 \cdot 96$

$(3 \cdot 33)$

0.216

$92 \cdot 586$

Each sample contains dextrine, glucosides, albumins, globulins, albuminoses, and substances which on hydrolysis yield pentoses.

The total percentages are in all cases below one hundred, and this is due to the fact that the alcohol extracts are not included in the total percentages. The extracts contain a considerable quantity of a resinous substance which was not identified with certainty owing to the methods for the determination of glucosides and tannins being unsatisfactory. $P$. vulgaris, however, contains a larger quantity of this resinous substance than either of the other two. This result is important, for it is stated by Jost that tannin would inhibit the action of diastase. This point, however, will be referred to again later.

The differences in the amounts of carbohydrates are not considerable, but the epigeal type ( $P$. vulgaris) contains the smaller quantity, the combined amounts of soluble carbohydrates, starch, and cellulose being :-

$\begin{array}{ccc}\text { P. multiflorus. } & \text { Vicia Faba. } & \text { P. vulgaris. } \\ \text { 58.815 }^{8} \mathrm{I}_{5} & 55.390 & 54.97\end{array}$

In regard to their proteids $P$. vulgaris contains a smaller amount as compared with $V$. Faba, but a slightly larger quantity as compared with $P$. multiflorus.

The 'diastatic value' was estimated as follows: A cold-water extract was made from the bean and so it contained no starch, as was shown by testing before making an estimation. Definite amounts of the extract were added to a dilute solution of pure starch. The tubes were immersed in a water bath at $40^{\circ} \mathrm{C}$. for one hour and then cooled and tested, after making sure no starch remained unconverted. The experiments were carried out by gaslight, but as the tubes were immersed from five to six inches in water they were removed from the influence of light. 
The smallest value is given for $V$. Faba and the greatest for P.multiflorus.

$P$. vulgaris contains a greater quantity of calcium oxalate than either of the other two.

The analyses show that the epigeal type contains less carbohydrates, about the same amount of proteid, but more resinous matter. Apart from the resinous substances the three seeds do not differ to any considerable extent quantitatively. It does not follow, however, that this ' ready manure' is equally available for use by the two types of seedling respectively. In the one case the food reserves are not normally exposed to the action of light, whilst in the other they are carried up into the light. It is quite possible that this latter fact is of importance, for J. R. Green (6) states that light has an inhibitory effect upon the action of diastase and so the starch may not be as available to the seedlings of the epigeal type as to those of the hypogeal type. The presence of a greater quantity of glucosides in the epigeal type may also interfere with the conversion of starch into soluble carbohydrate, for according to Jost this also has an inhibitory effect upon diastatic activity.

That there is a difference between the two types of food reserve and general organization of the developmental cycle is shown by the degree of dependence which each type of plant has on its reserves.

Young seedlings of $P$. multiflorus and $V$. faba were allowed to grow until the first pair of plumular leaves was unfolded. The cotyledons were then completely severed from the seedling and the plant permitted to continue its development. Growth is continued for a very short period only; the leaves expanded a little more, but sooner or later the mutilated seedlings died. During the same interval (Oct. I I-Nov. 3) the normal control plants grew about four feet in height.

A second batch of seedlings was then taken and allowed to grow until the first pair of plumular leaves was fully expanded; their cotyledons were then removed. In this case growth in length of the stem continued for a little while, but no new leaves were unfolded, the plant on the whole showing an etiolated appearance. More advanced stages of germination were taken, and it was found by this series of experiments that these plants were dependent upon their cotyledonary food reserves until they had expanded their third or fourth pair of leaves.

A similar set of experiments was made with the French Bean and Butter-bean. In these cases the cutting away of the cotyledonary food supply appeared in no way to affect the subsequent growth of the plants, the mutilated ones being indistinguishable from the controls.

From this series of experiments it would appear that, although the reserve food materials of the cotyledons may be very similar in the first instance, their immediate and relative availability to the two types of seed- 
ling is very different. The fact that the cotyledons are hypogeal in the one case suggests that the reserve food stored within them is sufficient to give the plant a good start in its development, such, at any rate, that it does not bring them above ground to assist in the processes of assimilation. On the other hand, the epigeal type brings its cotyledons into the service of the plant by enabling them to assist in assimilation. On the whole, then, it seems that the hypogeal type has an immediate and readily available stock of food, on which it draws largely when germination begins. In the case of the epigeal type of seedling it may well be that the cotyledonary food reserves are early used up in the growth of the cotyledons and the fairly long hypocotyl, and as a consequence the seedling has from the early stages acquired the habit of foraging for itself.

Then again, since the cotyledons of the epigeal type are carried into the light and become green, it is quite possible that the materials produced by photosynthesis become mixed up with the reserves, which in this way may be rendered less directly available for the plant.

With a view of testing this suggestion, seedlings were grown in the dark room and the plumular buds amputated as in previous experiments; controls were also kept under the same conditions. Fasciations were only obtained in those plants which show them under the other experimental condition. The seedlings of $P$. multiflorus produced good fasciations, but the epigeal types developed their cotyledonary shoots without showing any trace of fasciation. A second set of experiments was also made in which $P$. multiflorus seeds were germinated in the ordinary way and the plumules amputated as before. The cotyledons were then uncovered and the testa removed, so that the cotyledons were fully "exposed to the light. The exposure of the cotyledons, however, had no apparent effect on the plants' power to fasciate, for fasciations appeared in considerable numbers.

It would appear, then, that light is not the only determining factor, for the epigeal type does not fasciate when its cotyledons are removed from the influence of light, nor does the hypogeal type cease to fasciate when its cotyledons are brought under the influence of light.

Further experiments were made in which seedlings of the epigeal type were given a plentiful supply of nitrogenous manures. Although the unmutilated plants were very vigorous in their growth the mutilated plants did not produce any fasciated structures.

\section{Summary.}

I. The plants used in these experiments may be grouped in two classes: (I) Hypogeal types-Phaseolus multiflorus, Vicia Faba, and Pisum sativum; (2) Epigeal types-Phaseolus vulgaris, Phaseolus vulgaris, var.?, Lupinus Douglassii, Ricimus communis, and Cucurbita Pepo. 
2. Fasciations were induced in the former class but not in the latter.

3. The hypocotyl of hypogeal seedlings may be fasciated as a result of the adherence of a number of fasciated shoots. The vascular anatomy of such a structure is polystelic.

4. The food reserves in the two types of seedling may be similar, chemically, but the availability of that food is different for the two types of plants.

5. Hypogeal seedlings are remarkably dependent on their cotyledonary food reserves for their early development as contrasted with seedlings of the epigeal type.

My thanks are due to Prof. J. B. Farmer for suggesting that the work should be undertaken and for much valuable help and criticism during the earlier stages of the investigations; to Mr. W. Hales, of the Chelsea Physic Garden; where most of the experimental work was done, and also for much valuable advice on the culture of seedlings ; to Mr. T. J. Ward, of St. Mary's Hospital Medical School, for the analyses of some of the seeds; and to Mr. E. Lee for much friendly criticism during the preparation of the paper.

\section{BIBLIOGRAPHY.}

1. Blakeslee, A. F.: Zygospore Germinations in the Mucorinae. Ann. Mycol., iv, 1906, pp. I-27.

2. DE CANDolle, A. P.: Organographie végétale. I 827 .

3. Compton, R. H. : The Anatomy of the Mummy Pea. New Phyt., x, I9II, pp. 249-55.

4. Goebel, K.: Organography of Plants. Eng. ed., 1900.

5. — : Einleitung in die experimentelle Morphologie der Pflanzen. Naturw. und Technik in Lehre und Forschung, 1908.

6. Green, J. R. : On the Action of Light on Diastase and its Biological Significance. Phil. Trans. Roy. Soc., clxxxviii, B. I 897 , p. 167.

7. Hinks, W.: On the Nature of Fasciated Stems. Proc. Linn. Soc., ii, I853, p. 217.

8. KNight, T. A. : On Cultivation of Cockscomb. Trans. Hort. Soc. Lond., iv, I822, p. 32 I.

9. Knox, A. D. : Induction, Development, and Heritability of Fasciations. Proc. Carn. Instit. Washington, No. $98,1908$.

10. Klebs, G. : Zur Physiologie der Fortpflanzung einiger Pilze. Pringsh. Jahrb., xxxii.

11. Linnaeus, C. : Philosophia Botanica, I 75I, p. 2 I6.

12. MacDougal, D. T.: Alterations in Heredity induced by Ovarial Treatment. Bot. Gaz., li, I9II, Pp. 24I-56.

13. Masters, M. T.: Vegetable Teratology. I869.

14. Molliard, M. : Cas de virescence et de fasciation d'origine parasitaire. Rev. Gén. de Bot., xii, 1900, P. 323 .

15. Moquin-TANDon, A. : Éléments de tératologie végétale. Paris, I $84 \mathrm{I}$.

16. Petch, T. : The Physiology and Diseases of Hevea brasiliensis. London, I9I I, p. 240.

17. Peyritsch, J.: Ueber künstliche Erzeugung von gefüllten Bluithen und anderen Bildungsabweichungen. Sitzber. d. k. Akad. d. Wiss. in Wien, math.-naturw. Kl., xcvii, I888, p. 597. 
402 Reed.-Morphology and Physiology of Fasciated Seedlings.

18. Vöchting, H.: Untersuchungen zur experimentellen Anatomie und Pathologie des Pflanzenkörpers. Tübingen, i 908 .

19. DE VRIES, H. : On Biastrepsis in Relation to Cultivation. Ann. Bot., viii, I899, p. 396.

20. —— : Mutationstheorie, ii, p. 45I.

21. : Species and Varieties. Chicago, 1905.

22. - Sur la culture des fasciations des espèces annuelles et bisannuelles. Rev. Gén. de Bot., xi, 1899, pp. I36-5I.

23. Worsdell, W. C. : Fasciation, its Meaning and Origin. New Phyt., iv, pp. 55-74. 


\section{$2 \mathrm{BHL}$ Biodiversity Heritage Library}

Reed, T. 1912. "Some points in the morphology and physiology of fasciated seedlings." Annals of botany 26, 389-402. https://doi.org/10.1093/oxfordjournals.aob.a089396.

View This Item Online: https://www.biodiversitylibrary.org/item/236773

DOI: https://doi.org/10.1093/oxfordjournals.aob.a089396

Permalink: https://www.biodiversitylibrary.org/partpdf/319910

\section{Holding Institution}

Smithsonian Libraries

\section{Sponsored by}

Biodiversity Heritage Library

\section{Copyright \& Reuse}

Copyright Status: Not in copyright. The BHL knows of no copyright restrictions on this item.

This document was created from content at the Biodiversity Heritage Library, the world's largest open access digital library for biodiversity literature and archives. Visit BHL at https://www.biodiversitylibrary.org. 